\title{
Stability-indicating HPLC method for determination of amiodarone hydrochloride and its impurities in tablets: a detailed forced degradation study
}

\author{
Ana Silva Coelho', Igor Felipe Rodrigues Ribeiroํㅜ, Eduardo Burgarelli Lages ${ }^{\circledR 1 *}$
}

${ }^{1}$ Hipolabor Farmacêutica, Sabará, MG, Brazil

\begin{abstract}
Amiodarone hydrochloride is one of the most important drugs used to treat arrhythmias. The USP monograph for amiodarone hydrochloride describes an HPLC method for the quantification of seven impurities, however, this method shows problems that result in unresolved peaks. Moreover, there is no monograph for tablets in this compendium. Thus, a stability indicating HPLC method was developed for the determination of amiodarone, its known impurities and degradation products in tablets. A detailed forced degradation study was performed submitting amiodarone API, tablets and placebo to different stress conditions: acid and alkaline hydrolysis, oxidation, metal ions, heat, humidity, and light. Amiodarone hydrochloride API was susceptible to degradation in all stress conditions. The tablets also showed degradation in all environments, except in acidic condition. The analytes separation and quantification were achieved on an Agilent Zorbax Eclipse XDB-C18 column (100 x $3.0 \mathrm{~mm}, 3.5 \mu \mathrm{m})$. The mobile phase was composed of $50 \mathrm{mM}$ acetate buffer $\mathrm{pH} 5.5$ (A) and a mixture of methanol-acetonitrile (3:4, $\mathrm{v} / \mathrm{v}$ ) (B) in gradient elution. The method was validated in the range of $350-650 \mu \mathrm{g} / \mathrm{mL}$ for assay and 10-24 $\mu \mathrm{g} / \mathrm{mL}$ for impurities determination. Therefore, this method can be used both for stability studies and routine quality control analyses.
\end{abstract}

Keywords: Amiodarone hydrochloride. Impurities. Forced degradation. Stability indicating methods. High-performance liquid chromatography.

\section{INTRODUCTION}

Cardiovascular diseases are the number one cause of death in the world. It is estimated that 17.7 million people died in 2015 from cardiac diseases, representing $31 \%$ of all global deaths (WHO, 2018). Among cardiovascular diseases, arrhythmia can be defined as an abnormal heart rhythm. This means that the electrical impulses of the heart can happen faster, slower or erratically. Arrhythmias can range from asymptomatic and transitory clinical findings to life-threatening abnormalities (American Heart Association, 2018).

Amiodarone hydrochloride (Figure 1) is one of the drugs used to treat arrhythmias, although none of its pharmacological effects is clearly related to arrhythmiasuppressing properties (Mason, 1993). Oral amiodarone is indicated to treat patients with recurrent ventricular tachycardia, fibrillation resistant to other drugs and to

*Correspondence: E. B. Lages. Hipolabor Farmacêutica, BR 262, Km 12.3, Sabará, MG, Brazil. Tel: +55 31 36914926. E-mail: eduardoblages@gmail.com maintain sinus rhythm in patients with atrial fibrillation (Connolly, 1999). Despite its potential for serious adverse effects and uncertainties about its mechanism of action, amiodarone is one of the first-line drugs for the treatment of common cardiovascular diseases (Roden, 2010).

Amiodarone hydrochloride is used worldwide and its monograph is described in a large number of pharmacopeias, including the United States Pharmacopoeia (USP, 2017) and the British Pharmacopoeia (BP, 2018). The monographs for amiodarone hydrochloride raw material presented in those pharmacopeias describe an isocratic reversed-phase HPLC method for the quantification of seven impurities (A-G) (Figure 1). The same analytical conditions are presented for amiodarone tablets monographs in BP and USP Pharmacopeial Forum. Additionally, these compendia report other methods for the quantitative amiodarone assay (BP, 2018; USP, 2018).

Karmakar et al. (2014) observed problems with the USP method for amiodarone related substances that resulted in unresolved peaks due to impurities A, D and E. The authors optimized the USP method using quality 
Amiodarone hydrochloride<smiles>CCCCc1oc2ccccc2c1C(=O)c1cc(I)c(OCCN(CC)CC)c(I)c1</smiles>

Amiodarone related compound B<smiles>CCCCc1oc2ccccc2c1C(=O)c1cc(I)c(OCCNCC)c(I)c1</smiles>

Amiodarone related compound D<smiles>CCCCc1oc2ccccc2c1C(=O)c1cc(I)c(O)c(I)c1</smiles>

Amiodarone related compound F<smiles>CCCCc1oc2ccccc2c1C(=O)c1ccc(O)c(I)c1</smiles>

Amiodarone related compound A<smiles>CCCCc1oc2ccccc2c1C(=O)c1ccc(OCCN(CC)CC)cc1</smiles>

Amiodarone related compound C<smiles>CCCCc1oc2ccccc2c1C(=O)c1ccc(OCCN(CC)CC)c(I)c1</smiles>

\section{Amiodarone related compound E}<smiles>CCCCc1oc2ccccc2c1C(=O)c1ccc(O)cc1</smiles>

Amiodarone related compound G<smiles>CCC[C@H](OC)c1oc2ccccc2c1C(=O)c1cc(I)c(OCCN(CC)CC)c(I)c1</smiles>

FIGURE 1 - Chemical structures of amiodarone hydrochloride and its impurities (A-G).

by design approach and altered the column brand, column temperature and $\mathrm{pH}$ of the mobile phase. However, they did not perform a forced degradation study to verify the separation of the related compounds in the presence of degradation products.

It is known that forced degradation tests are the main tool to predict drug degradation, to identify possible degradation products of an active pharmaceutical ingredient (API) or drug product and to develop stability indicating methods. Therefore, it is not possible to guarantee that a method is stability indicating only because it is capable of separating some known impurities (Baertschi, Alsante, Reed, 2011; Bakshi, Singh, 2002; Silva et al., 2009).

Khan et al. (2005) developed an isocratic HPLC method for the estimation of purity and quantitative determination of amiodarone API in the presence of five of its known impurities. In order to demonstrate the specificity of the method, samples of amiodarone were subjected to various stress conditions such as acid, base, hydrogen peroxide, heat, humidity, and light. Amiodarone presented significant degradation ( $8 \%$ ) only under acidic hydrolysis.

Christopherson, Yoder, and Miller (2004) developed a gradient HPLC method for the determination of amiodarone and two of its known impurities in amiodarone injection. The authors described a degradation study submitting amiodarone to acid, base, peroxide, heat and light conditions. Amiodarone was stable under all conditions, except for photolytic treatment (13\% degradation).

Despite being an important and widely used drug, there are only a few studies reporting the stability of 
amiodarone under stress conditions. Furthermore, the stability indicating methods described do not prove to be able to resolve the peaks due to the seven known amiodarone impurities and the degradation products.

In this context, the aim of this study was to perform a detailed and comprehensive study to evaluate the stability of amiodarone in API and tablets under acidic, alkaline, oxidative, heat, humidity and light conditions and in the presence of metal ions, according to current legislation (Anvisa, 2015). Furthermore, a simple and selective gradient HPLC stability indicating method for quantification of amiodarone and its seven related compounds in the presence of its degradation products was developed and validated.

\section{MATERIAL AND METHODS}

\section{Reagents and standards}

Amiodarone hydrochloride reference standard was obtained from Fiocruz (Rio de Janeiro, Brazil). Impurities $D$ and $E$ were purchased from U.S. Pharmacopeial Convention (Rockville, USA) and impurities A, B, C, F, and $G$ were obtained from PGS (San Francisco, EUA). Tablets containing $200 \mathrm{mg}$ of amiodarone hydrochloride and placebo were provided by Hipolabor Farmacêutica (Sabará, Brazil). Amiodarone hydrochloride API was purchased from Zhejiang Sanmen (Sanmen, China). The reagents used for the analysis were: acetonitrile (ACN), methanol $(\mathrm{MeOH})$ and dimethyl sulfoxide (DMSO) from Merck (Darmstadt, Germany), hydrogen peroxide from Soltech (Rio de Janeiro, Brazil) and acetic acid, hydrochloric acid, iron (III) sulfate, ammonium hydroxide and sodium hydroxide from Neon (São Paulo, Brazil). Purified water was obtained from an Elga Purelab Option-Q system.

\section{Preparation of mobile phase and diluent}

The diluent was prepared by mixing $500 \mathrm{~mL}$ of $\mathrm{ACN}$ and $500 \mathrm{~mL}$ of purified water. Mobile phase A was prepared by mixing $3 \mathrm{~mL}$ of acetic acid and $1000 \mathrm{~mL}$ of purified water. In the optimized phase, $\mathrm{pH}$ was adjusted to 5.5 with ammonium hydroxide. Mobile phase $\mathrm{B}$ was composed of $300 \mathrm{~mL}$ of $\mathrm{MeOH}$ and $400 \mathrm{~mL}$ of ACN. After preparation, both mobile phases were filtered through a $0.22 \mu \mathrm{m}$ filter.

\section{Instrumentation and analytical conditions}

Chromatography was carried out using a Thermo Ultimate 3000 HPLC system equipped with a quaternary gradient pump, an autosampler, a column oven, and a photodiode array detector. Software Chromeleon 7 was used for data acquisition and analysis. Separation was performed on an Agilent Zorbax Eclipse XDB-C18 column $(100 \times 3.0 \mathrm{~mm}, 3.5 \mu \mathrm{m})$. After optimization, the column was maintained at $50{ }^{\circ} \mathrm{C}$. A gradient elution was used (Table I), with a flow rate of $0.7 \mathrm{~mL} / \mathrm{min}$. The injection volume was $2 \mu \mathrm{L}$ and UV detection was performed at $240 \mathrm{~nm}$.

TABLE I - Mobile phase gradient used

\begin{tabular}{ccc}
\hline Time (min) & $\begin{array}{c}\text { Mobile } \\
\text { phase A (\%) }\end{array}$ & $\begin{array}{c}\text { Mobile } \\
\text { phase B (\%) }\end{array}$ \\
\hline 0.0 & 35 & 65 \\
25.0 & 15 & 85 \\
25.1 & 35 & 65 \\
35.0 & 35 & 65 \\
\hline
\end{tabular}

Mobile phase A: $50 \mathrm{mM}$ acetate buffer $\mathrm{pH}$ 5.5; Mobile phase B: mixture of methanol-acetonitrile $(3: 4, \mathrm{v} / \mathrm{v})$.

\section{Preparation of impurities mix standard for method development}

Separate standard stock solutions of amiodarone hydrochloride and of each impurity (A-G) at a concentration of $500 \mu \mathrm{g} / \mathrm{mL}$ were prepared by dissolving an accurately weighed amount of $5 \mathrm{mg}$ in $10 \mathrm{~mL}$ of methanol. Then, aliquots of $1 \mathrm{~mL}$ of each stock solution were taken and transferred to a $10 \mathrm{~mL}$ volumetric flask. The volume was completed with diluent. The final concentration of each analyte was $50 \mu \mathrm{g} / \mathrm{mL}$.

\section{Preparation of standard and sample solutions for the assay testing}

The assay test was performed at $500 \mu \mathrm{g} / \mathrm{mL}$ of amiodarone hydrochloride. The standard stock solution was prepared by weighing $50 \mathrm{mg}$ of amiodarone hydrochloride reference standard and transferring to a $50 \mathrm{~mL}$ volumetric flask. The volume was completed with methanol. Then, an aliquot of $5 \mathrm{~mL}$ of this solution was taken and transferred to a $10 \mathrm{~mL}$ volumetric flask. The volume was completed with diluent. For the sample preparation, 20 tablets were accurately weighed and ground to fine powder. An amount of powder equivalent to $50 \mathrm{mg}$ of amiodarone hydrochloride was dissolved in $50 \mathrm{~mL}$ of methanol. An aliquot of $5 \mathrm{~mL}$ of this solution was taken and transferred to a $10 \mathrm{~mL}$ volumetric flask. The volume was completed with diluent. 


\section{Preparation of standard and sample solutions for impurities determination}

The sample solution was prepared at a concentration of $10 \mathrm{mg} / \mathrm{mL}$ for amiodarone hydrochloride, dissolving an amount of powder equivalent to $100 \mathrm{mg}$ of amiodarone hydrochloride in $10 \mathrm{~mL}$ of methanol. The standard solution was prepared at a concentration of $20 \mu \mathrm{g} / \mathrm{mL}$ of amiodarone hydrochloride, corresponding to the specified limit for impurities $(0.2 \%)$. An aliquot of $4 \mathrm{~mL}$ of the assay standard solution $(500 \mu \mathrm{g} / \mathrm{mL})$ was taken and transferred to a $100 \mathrm{~mL}$ volumetric flask. The volume was completed with diluent. All impurities were calculated in comparison to the amiodarone peak.

\section{Forced degradation}

A comprehensive forced degradation study was performed submitting amiodarone hydrochloride API, tablets and placebo to different stress conditions: acidic, alkaline, oxidative, metal ions, heat, humidity, and light. In dry heat condition, the API, placebo and tablets powder were submitted to high temperature $\left(105^{\circ} \mathrm{C}\right.$ in an oven $)$ for seven days. The influence of humidity on stability was tested by exposing the samples powders in a 420/CLD stability cabinet (Nova Ética) to $40^{\circ} \mathrm{C}$ and $75 \pm 5 \%$ relative humidity for five days. Light stress studies were performed subjecting the samples powder to the UV-A radiation (200 Wh/ $\left.\mathrm{m}^{2}\right)$ and visible radiation (1.2 million lux-hours) during five days. To prepare the samples submitted to hydrolytic degradation, oxidation (with hydrogen peroxide) and degradation by metal ions, approximately $50 \mathrm{mg}$ of amiodarone hydrochloride were accurately weighed and transferred to $50 \mathrm{~mL}$ volumetric flasks, followed by the addition of $5 \mathrm{~mL}$ of cosolvent (DMSO was used for alkaline hydrolysis and $\mathrm{MeOH}$ for the other conditions). Then, $10 \mathrm{~mL}$ of degradation solutions were added, and the samples were exposed to the following conditions: acid hydrolysis $\left(5.0 \mathrm{M} \mathrm{HCl}\right.$ solution at $25^{\circ} \mathrm{C}$ for 5 days), alkaline hydrolysis ( $1.0 \mathrm{M} \mathrm{NaOH}$ solution at $60{ }^{\circ} \mathrm{C}$ for 15 hours), oxidation $\left(30 \% \mathrm{H}_{2} \mathrm{O}_{2}\right.$ solution at $25^{\circ} \mathrm{C}$ for 3 days $)$ and metal ions $\left(0.1 \mathrm{M} \mathrm{Fe}_{2}\left(\mathrm{SO}_{4}\right)_{3}\right.$ solution at $25^{\circ} \mathrm{C}$ for 2 days). After this period, resulting solutions were neutralized, if applicable, and diluted to $50 \mathrm{~mL}$ with methanol. Then, aliquots of $5 \mathrm{~mL}$ of each solution were taken and transferred to $10 \mathrm{~mL}$ volumetric flasks. The volume was completed with diluent. These solutions were filtered and injected in the chromatographic system. Solutions of placebo and diluent employed for preparing the samples in each stress condition were injected in order to evaluate the presence of possible interference peaks.
The control samples were also prepared without adding the degradation solutions to quantify the percentages of amiodarone degradation.

\section{Method validation}

The stability-indicating method was validated for assay and related substances following the recommendations described in the Brazilian legislation $\mathrm{RDC} \mathrm{N}^{\mathrm{o}}$ 166/2017 (Anvisa, 2017) and in ICH Guidance for Industry Q2 (R1) Validation of Analytical Procedures: Text and Methodology (ICH, 2005). Some acceptance criteria applied were defined based on the Guidelines for Standard Method Performance Requirements (AOAC, 2016). The following parameters were evaluated: selectivity, limit of detection (LOD) and limit of quantification (LOQ), linearity, precision, accuracy, robustness, and stability of solutions.

\section{Selectivity}

Selectivity of the developed method was proved by stress degradation studies in which the drug was intentionally degraded under different stress conditions (Anvisa, 2015). The presence of interferents in the retention time of amiodarone and its known impurities was evaluated. The acceptance criteria for adequate separation was the resolution value greater than 1.5. Moreover, the peak purity was analyzed using a photodiode array detector.

\section{$\angle O D$ and $L O Q$}

Limits of detection and quantitation were estimated at a signal to noise ratio of $3: 1$ and 10:1 respectively, according to ICH (2005). For this approach, decreasing analyte concentrations were analyzed.

\section{Linearity}

Linearity was evaluated in two ranges, one for impurities and the other for assay. For impurities determination, linearity was evaluated at six concentration levels, corresponding from $0.10 \%$ to $0.24 \%$ of the working concentration $(10 \mathrm{mg} / \mathrm{mL})$. The linearity of the assay was determined in the range from $70 \%$ to $130 \%$ of the working concentration $(500 \mu \mathrm{g} / \mathrm{mL})$ using five different concentration levels. In both cases, solutions were prepared in triplicate. The obtained data were statistically analyzed to prove that they met the assumptions for a linear regression. The Grubbs test was used in order to evaluate the presence of outliers. Shapiro-Wilk and Cochran tests were performed to assess the normality and homoscedasticity of residuals, respectively (Cochran, 
1941; Shapiro, Wilk, 1965; Souza, Junqueira, 2005). Also, the regression significance and adjustment to the linear model were evaluated.

\section{Precision}

For the impurities method, the intra-day precision was evaluated by carrying out six preparations of placebo spiked with amiodarone hydrochloride at $0.20 \%$ of nominal sample concentration. The inter-day precision was performed by repeating the same procedure on another day by another analyst. The precision of the assay method was assessed in terms of intra-day and inter-day precision by the quantification of amiodarone in six independent replicates prepared at $100 \%$ of the working concentration. Results were reported in terms of relative standard deviation (RSD).

\section{Accuracy}

To assess accuracy, placebo was spiked with known amounts of amiodarone hydrochloride in three levels: $0.10 \%, 0.20 \%$ and $0.24 \%$ of the working concentration for impurities (10 mg/mL) and $70 \%, 100 \%$ and $130 \%$ of the working concentration for the assay $(500 \mu \mathrm{g} / \mathrm{mL})$. Each solution was prepared in triplicate and the recovery percentage of amiodarone was calculated.

\section{Robustness}

The robustness of the method was evaluated analyzing samples prepared in the precision test. Samples were assayed under nominal conditions and by the variation of the following analytical parameters: column temperature $\left(48\right.$ and $\left.52^{\circ} \mathrm{C}\right)$, flow rate $(0.6$ and $0.8 \mathrm{~mL} / \mathrm{min})$, buffer $\mathrm{pH}$ (5.3 and 5.7) and column batch. Moreover, the retention factor, tailing factor, and theoretical plate number were evaluated for five injections of the standard solution in each condition to set the system suitability parameters.

\section{Stability of solutions}

The standards and samples solutions used in the precision test were stored in the autosampler in amber glass vials at $10^{\circ} \mathrm{C}$. Solutions were analyzed by the HPLC instrument at different time intervals $(0 \mathrm{~h}, 24 \mathrm{~h}, 48 \mathrm{~h}$, and $72 \mathrm{~h})$.

\section{RESULTS AND DISCUSSION}

\section{Method optimization}

In order to optimize the stability indicating method, the impurity mixture standard was employed. Different columns were used and the best results were obtained with Agilent Zorbax Eclipse XDB-C18 (100 x 3.0 mm, $3.5 \mu \mathrm{m})$. The column temperature was tested in the range of $25^{\circ} \mathrm{C}$ to $50^{\circ} \mathrm{C}$. The peak shape was improved increasing temperature. Thus, the temperature was set at $50^{\circ} \mathrm{C}$. It is known that changes in the $\mathrm{pH}$ of the mobile phase are one of the best strategies to enhance the resolution between acidic or basic substances. Amiodarone hydrochloride is a weak base with a pKa value of 6.56 . The pka values for the impurities were predicted using MarvinSketch software (ChemAxon, Budapest, Hungary) and the following values were obtained: 8.58 (impurity A), 9.40 (impurity B), 8.52 (impurity C), 5.61 (impurity D), 7.80 (impurity E), 6.70 (impurity F) and 8.47 (impurity G). Amiodarone and its impurities have similar chemical structures and properties. Because of that, it is hard to predict the behavior of these analytes, especially considering $\mathrm{pKa}$ only. Thus, during the method development, the $\mathrm{pH}$ of the buffer was tested in the range of 3.0 to 6.0 . The resolution between the critical peak pair (impurities $\mathrm{E}$ and $\mathrm{A}$ ) was higher with $\mathrm{pH}$ 5.5, therefore, this condition was set. Several gradients were tested and the one with the best results is shown in Table I. The chosen wavelength was $240 \mathrm{~nm}$, once amiodarone and its impurities showed a good absorption at this condition. The chromatogram obtained for the standard mixture, in the optimized condition, is shown in Figure 2.

\section{Forced degradation}

Table II shows a summary of the results obtained in the forced degradation study for both API and tablets. In acidic hydrolysis, $5.0 \mathrm{M} \mathrm{HCl}$ was used for 120 hours. Amiodarone API showed around 10\% degradation, while amiodarone tablets were stable. The only degradation product formed with amiodarone API was impurity B. In alkaline hydrolysis, amiodarone API and tablets were exposed to $1.0 \mathrm{M} \mathrm{NaOH}$ for 15 hours at $60{ }^{\circ} \mathrm{C}$ in an oven. Both API and tablets showed degradation over $20 \%$. The chromatogram obtained for amiodarone tablets is shown in Figure 3. Impurity D was formed, with several unknown impurities. Two kinds of oxidations mechanisms were tested. With $30 \% \mathrm{H}_{2} \mathrm{O}_{2}$ for 96 hours, both API and tablets showed degradation over $20 \%$. The chromatogram obtained for tablets is shown in Figure 4. There was a formation of one unknown impurity, with a relative retention time (RRT) of 0.47 , and impurities $\mathrm{B}, \mathrm{C}$ and D. With $0.1 \mathrm{M} \mathrm{Fe}_{2}\left(\mathrm{SO}_{4}\right)_{3}$ for 48 hours, only amiodarone API showed degradation over 10\%. Impurities B and D were formed in this condition. When exposed to dry heat $\left(105^{\circ} \mathrm{C}\right.$ for 168 hours $)$, amiodarone tablets and API showed degradation around 10\%. Impurities B, C, D, E, and $\mathrm{F}$ were formed for amiodarone tablets, as well as an 


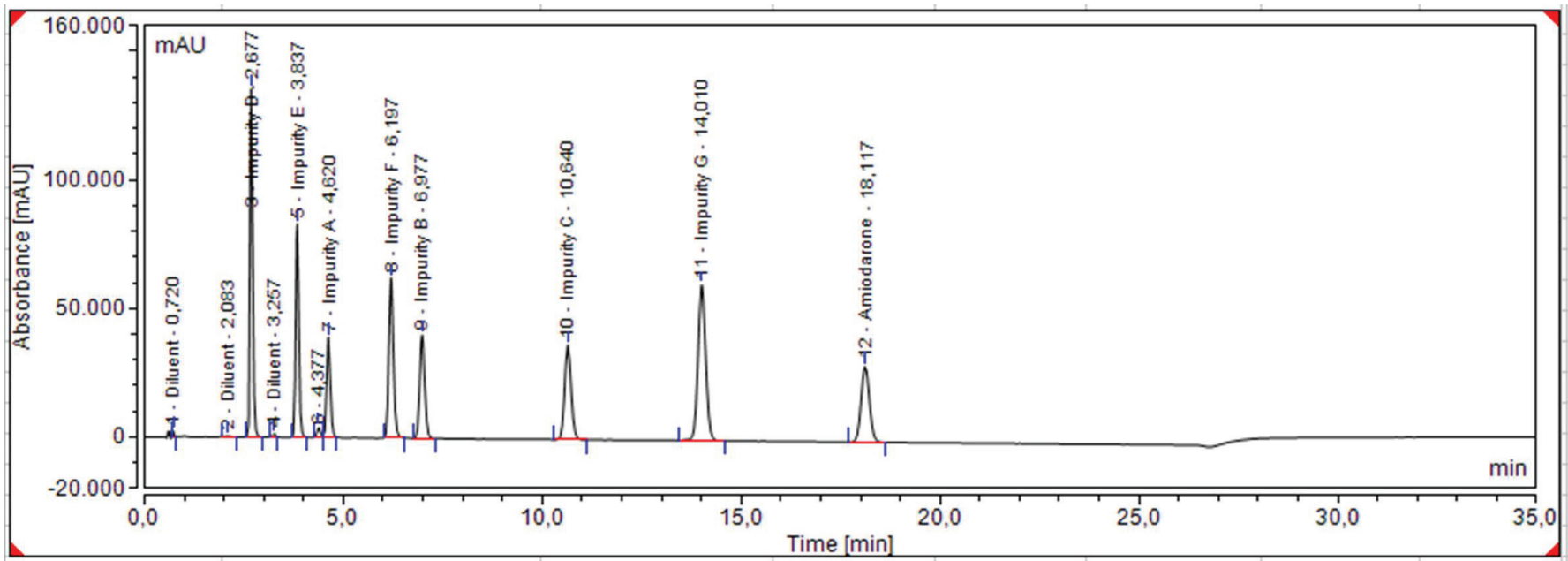

FIGURE 2 - Representative chromatogram of the impurity mixture standard.

unknown impurity with RRT of 0.47 . The chromatogram obtained is shown in Figure 5. After exposure to humid heat $\left(40{ }^{\circ} \mathrm{C}\right.$ and $75 \%$ R.H. for 120 hours), only amiodarone API showed degradation over $10 \%$. Two unknown impurities were formed, with RRT of 0.47 and 0.59 . Also, impurities B and D were formed, for both API and tablets. Amiodarone API was more susceptible to photolysis than tablets when exposed to UV light for 120 hours. After the exposure, there was a formation of impurities B, C and D and an unknown impurity with RRT of 0.47 . The extent of degradation under all conditions tested was lower for tablets than for API. The main degradation products formed in all conditions were impurities B, C and D and an unknown impurity with RRT of 0.47 . The optimized method was able to resolve the peaks due to amiodarone, its known impurities, and degradation products.

A literature survey revealed that only two forced degradation studies for amiodarone hydrochloride are to be found (Christopherson, Yoder, Miller, 2004; Khan et al.,
TABLE II - Results obtained in the forced degradation study for amiodarone API and tablets

\begin{tabular}{lcc}
\hline \multirow{2}{*}{ Stress conditions } & \multicolumn{2}{c}{ Degradation (\%) } \\
\cline { 2 - 3 } & $\begin{array}{c}\text { Amiodarone } \\
\text { API }\end{array}$ & $\begin{array}{c}\text { Amiodarone } \\
\text { tablets }\end{array}$ \\
\hline $5.0 \mathrm{M} \mathrm{HCl}-120 \mathrm{~h}$ & 9.51 & 1.97 \\
$1.0 \mathrm{M} \mathrm{NaOH}-60{ }^{\circ} \mathrm{C}-15 \mathrm{~h}$ & 30.82 & 20.35 \\
$30 \% \mathrm{H}_{2} \mathrm{O}_{2}-96 \mathrm{~h}$ & 34.93 & 21.61 \\
$0.1 \mathrm{M} \mathrm{Fe}_{2}\left(\mathrm{SO}_{4}\right)_{3}-48 \mathrm{~h}$ & 30.82 & 7.89 \\
$105{ }^{\circ} \mathrm{C}-168 \mathrm{~h}$ & 11.99 & 8.38 \\
$40{ }^{\circ} \mathrm{C}, 75 \% \mathrm{R} . \mathrm{H} .-120 \mathrm{~h}$ & 15.04 & 6.92 \\
$\mathrm{UV}$ light $-120 \mathrm{~h}$ & 16.44 & 7.11 \\
\hline
\end{tabular}

2005). However, both used mild stress conditions that resulted in a small extent of amiodarone degradation. In this study, the stress conditions employed resulted

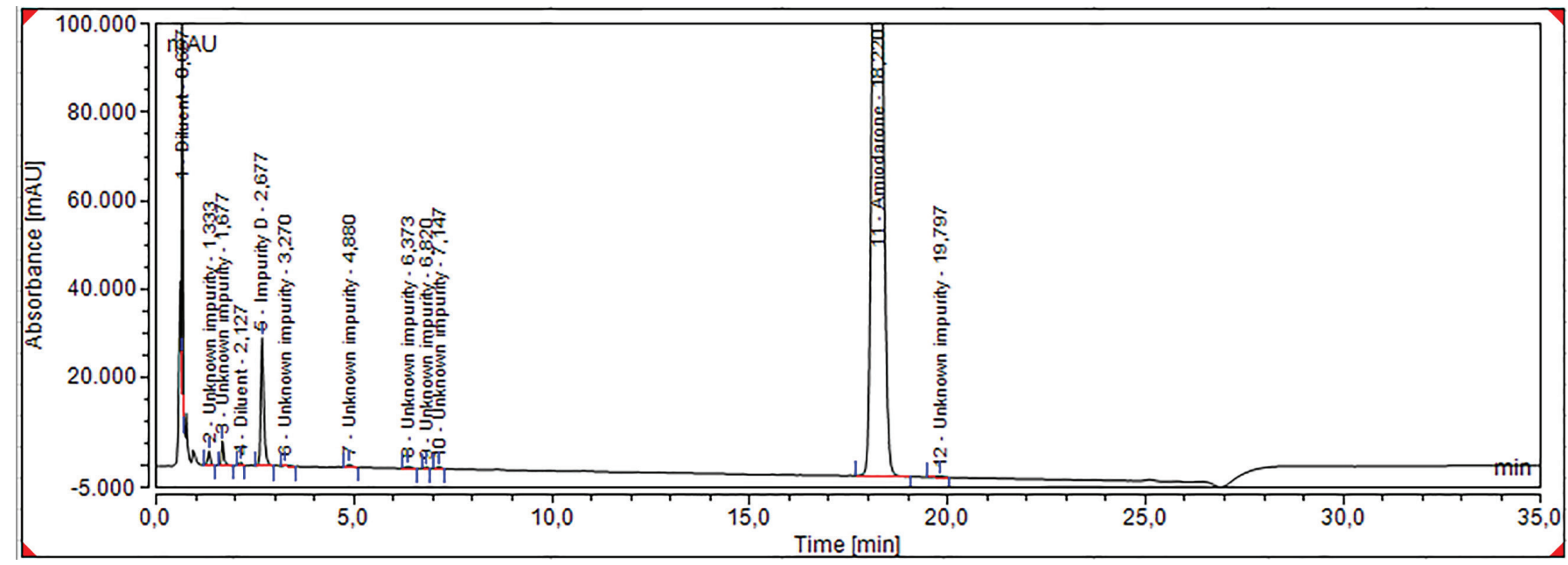

FIGURE 3 - Representative chromatogram of amiodarone hydrochloride tablets after degradation by alkaline hydrolysis. 


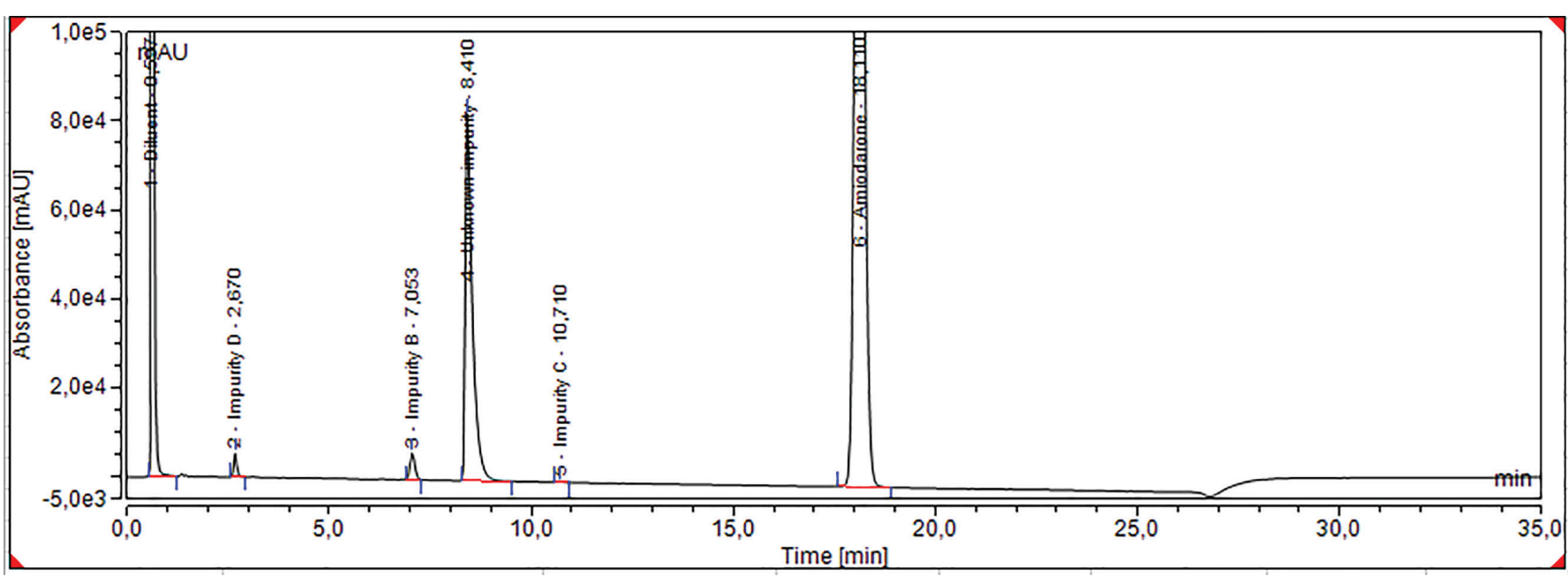

FIGURE 4 - Representative chromatogram of amiodarone hydrochloride tablets after degradation by oxidation.

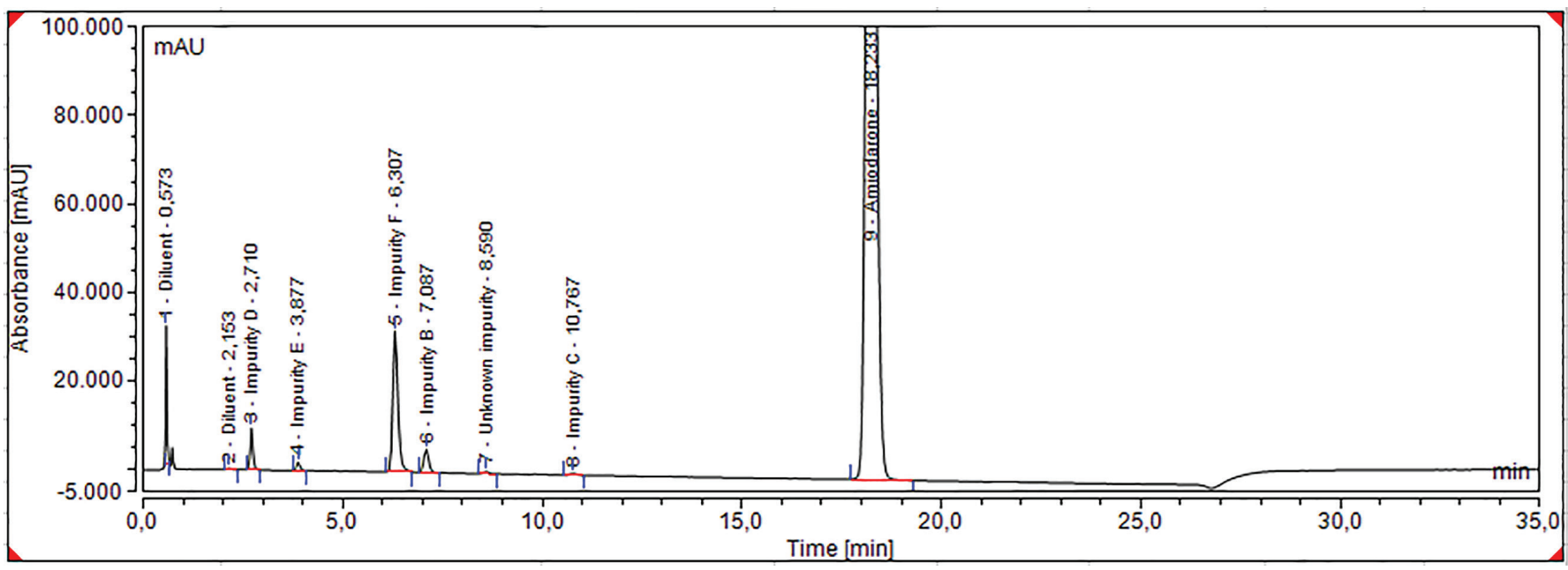

FIGURE 5 - Representative chromatogram of amiodarone hydrochloride tablets after degradation by dry heat exposure.

in amiodarone degradation under all conditions and in adequate extension (about 10 to 30\%). It is hard to compare the degradations obtained, once the pharmaceutical forms used are different and API from different manufacturers can lead to distinct degradation profiles.

\section{Method validation}

\section{Selectivity}

The selectivity of the method was investigated by injecting the stress samples. There were no peaks eluting in the same retention time than amiodarone, its related substances or degradation products peaks. All peaks were well separated and the resolution was in all cases not less than 1.5. Moreover, a photodiode array detector was used to scan the amiodarone and all known impurities peaks in the range from 200 to $400 \mathrm{~nm}$. Spectra indicated that no co-elution was present, once the purity match was above 950, according to Chromeleon 7 software.

\section{$\angle O D$ and $L O Q$}

Employing the signal-to-noise ratio method, the detection and quantitation limits were $8 \mu \mathrm{g} / \mathrm{mL}$ and $9 \mu \mathrm{g} /$ $\mathrm{mL}$, respectively.

\section{Linearity}

Statistical tests were used to verify if the obtained data met the premises for the use of the ordinary least squares method. The results obtained for the tests of normality and homoscedasticity of residuals showed that the residuals are in agreement with all the least squares method assumptions. Moreover, the residuals presented random distribution, the regression was statistically significant and lack of adjustment to the linear model was not observed. The equations of the calibration curves obtained were $y=147.54 x+44.734$ for impurities method and $y=151.12 x-877.23$ for assay method. For both of them, the correlation coefficient was higher than 0.990, as required by the validation guideline (Anvisa, 2017). 


\section{Precision}

For the impurities method, the RSD obtained was $5.2 \%$, for both intra-day and inter-day precision. Concerning the assay method, the RSD obtained in the intra-day and inter-day precision were $1.0 \%$ and $1.2 \%$, respectively (Table III). The developed method was found to be precise as the RSD values were less than $5.3 \%$ for impurities and 2.0\% for the assay (AOAC, 2016).

TABLE III - Amiodarone hydrochloride precision (*data are means $\pm \mathrm{SD}$ )

\begin{tabular}{lccc}
\hline & $\begin{array}{c}\text { Theoretical } \\
\text { concentration } \\
(\mathbf{\%})\end{array}$ & $\begin{array}{c}\text { Concentration } \\
\text { obtained } \\
(\%)\end{array}$ & $\begin{array}{c}\text { RSD } \\
(\mathbf{\%})\end{array}$ \\
\hline Impurities & & & \\
\hline Day 1 (n=6) & 0.20 & $0.20 \pm 0.01$ & 5.2 \\
Day 2 (n=6) & 0.20 & $0.19 \pm 0.01$ & 5.2 \\
Inter-day (n=12) & 0.20 & $0.19 \pm 0.01$ & 5.2 \\
\hline Assay & & & \\
\hline Day 1 (n=6) & 100.00 & $102.53 \pm 1.02$ & 1.0 \\
Day 2 (n=6) & 100.00 & $101.28 \pm 0.99$ & 1.0 \\
Inter-day (n=12) & 100.00 & $101.90 \pm 1.17$ & 1.2 \\
\hline SD: stan
\end{tabular}

SD: standard deviation

\section{Accuracy}

Accuracy was assessed using placebo solutions spiked with known amounts of amiodarone hydrochloride in three levels. The recovery percentages were between 90.0 and $107.0 \%$ for impurities and 98.0 and $102.0 \%$ for assay. Moreover, the RSD values were below 5.3\% and $2.0 \%$, respectively (Table IV) (AOAC, 2016).

\section{Robustness}

In the robustness study, each chromatographic factor selected was changed one by one to estimate the effect of the change on the results. The method was not robust only for changes in the $\mathrm{pH}$ of the buffer solution, and therefore, this parameter must be properly controlled.

\section{Stability of solutions}

Solutions were considered stable for 72 hours since no evidence of degradation of the analyte was observed until this time.

\section{CONCLUSIONS}

A comprehensive stability study was carried out, subjecting samples of amiodarone hydrochloride API and tablets to degradation by acid and alkaline
TABLE IV - Amiodarone hydrochloride recovery (data are means $\pm \mathrm{SD}, \mathrm{n}=3$ )

\begin{tabular}{lcc}
\hline $\begin{array}{l}\text { Theoretical } \\
\text { concentration (\%) }\end{array}$ & $\begin{array}{c}\text { Recovery (\%) } \\
\text { (mean } \pm \text { SD) }\end{array}$ & RSD (\%) \\
\hline Impurities & & \\
\hline 0.10 & $98.85 \pm 0.28$ & 0.29 \\
0.20 & $97.66 \pm 1.26$ & 1.29 \\
0.24 & $96.79 \pm 1.39$ & 1.43 \\
\hline Assay & & \\
\hline 70 & $99.72 \pm 0.72$ & 0.72 \\
100 & $99.16 \pm 0.68$ & 0.69 \\
130 & $98.57 \pm 0.88$ & 0.89 \\
\hline
\end{tabular}

SD: standard deviation

hydrolysis, oxidation, metal ions, heat, humidity, and light. Amiodarone hydrochloride API was susceptible to degradation in all stress conditions. The tablets also showed degradation in all environments, except in acidic condition. Moreover, in all cases, the extent of degradation for the tablets was lower than for the API. In this sense, the use of proper adjuvants and packaging materials should be considered during drug product development. The developed stability-indicating method was completely validated showing to be selective, linear, precise, accurate and robust and can be used both for stability studies and routine quality control analyses.

\section{ACKNOWLEDGMENTS}

The authors thank Pedro Henrique Gouvêa, Clara Coelho and Raquel Arribada for the assistance in the preparation of the manuscript. This research did not receive any specific grant from funding agencies in the public, commercial, or not-for-profit sectors.

\section{REFERENCES}

American Heart Association. About Arrhythmia. [cited 2018 Jan 18]. Available from: http://www.heart.org/HEARTORG/ Conditions/Arrhythmia/AboutArrhythmia/About-Arrhythmia UCM_002010_Article.jsp\#.WYdWMojyvIV.

Agência Nacional de Vigilância Sanitária. ANVISA. Resolução RDC n. 166, de 24 de Julho de 2017. Brasília: Ministério da Saúde; 2017. 
Agência Nacional de Vigilância Sanitária. ANVISA. Resolução RDC n. 53, de 4 de Dezembro de 2015. Brasília: Ministério da Saúde; 2015.

Baertschi SW, Alsante KM, Reed RA. Pharmaceutical Stress Testing: Predicting Drug Degradation. London: Informa Healthcare; 2011.

Bakshi M, Singh S. Development of validated stabilityindicating assay methods-critical review. J Pharm Biomed Anal. 2002;28(6):1011-40.

British Pharmacopoeia 2018. BP. London: British Pharmacopoeia Commission Office; 2018.

Christopherson MJ, Yoder KJ, Miller RB. Validation of a stability-indicating HPLC method for the determination of amiodarone $\mathrm{HCl}$ and its related substances in amiodarone $\mathrm{HCl}$ injection. J Liq Chromatogr Relat Technol. 2004;27(1):95-111.

Cochran WG. The distribution of the largest of a set of estimated variances as a fraction of their total. Ann Hum Genet. 1941;11(1):47-52.

Connolly SJ. Evidence-based analysis of amiodarone efficacy and safety. Circulation. 1999;100(19):2025-34.

International Conference on Harmonization. ICH. Validation of Analytical Procedures: Text and Methodology Q2 (R1). Geneva: International Conference on Harmonization; 2005.

International Official Methods of Analysis. AOAC. Appendix F: Guidelines for Standard Method Performance Requirements. Rockville: International Official Methods of Analysis; 2016.

Karmakar S, Yang X, Garber R, Szajkovics A, Koberda M. Quality by design (QbD) based development and validation of an HPLC method for amiodarone hydrochloride and its impurities in the drug substance. J Pharm Biomed Anal. 2014;100:167-74.
Khan MA, Kumar S, Jayachandran J, Vartak SV, Bhartiya A, Sinha S. Validation of a stability indicating LC method for amiodarone $\mathrm{HCl}$ and related substances. Chromatographia. 2005;61(11-12):599-607.

Mason JW. A comparison of seven antiarrhythmic drugs in patients with ventricular tachyarrhythmias: electrophysiologic study versus electrocardiographic monitoring investigators. $\mathrm{N}$ Engl J Med. 1993;329(7):452-58.

Roden DM. Fármacos antiarrítmicos. In: Brunton LL, editor. Goodman \& Gilman: As Bases Farmacológicas da Terapêutica. Porto Alegre: AMGH; 2010. p. 805-836.

Silva KER, Alves LDS, Soares MFR, Passos RCS, Faria AR, Rolim Neto PJ. Modelos de avaliação da estabilidade de fármacos e medicamentos para a indústria farmacêutica. Rev Ciênc Farm Básica Apl. 2009;30(2):129-135.

Shapiro SS, Wilk MB. An analysis of variance test for normality (complete samples). Biometrika. 1965;52(3):591-611.

Souza SVC, Junqueira RG. A procedure to assess linearity by ordinary least squares method. Anal Chim Acta. 2005;552(12):25-35.

The United States Pharmacopeia. Pharmacopeial Forum Online. [cited 2018 Jun 05]. Available from: http://www.usppf.com/pf/ pub/index.html.

The United States Pharmacopoeia and National Formulary. USP. USP40 - NF35. Rockville, MD: The United States Pharmacopoeial Convention; 2017.

World Health Organization. WHO. Cardiovascular diseases (CVDs). [cited 2018 Jan 18]. Available from: http://www.who. int/mediacentre/factsheets/fs317/en/.

Received for publication on $09^{\text {th }}$ April 2018 Accepted for publication on $22^{\text {nd }}$ August 2018 